\title{
Erratum to: The Business School: Serving Mammon or the University
}

David Gautschi and Jonathan Story

\author{
A. Erisman et al. (eds.), The Purpose of Business \\ (C) Albert Erisman and David Gautschi 2015
}

\section{DOI 10.1057/9781137503244_14}

The original version of this chapter contained error which has been corrected.

The correction is given below:

The information for figure 1.1 given in this chapter was originally as "Figure 1.1 Four Bad Bears Adjusted for Inflation" without the Source information. This has been updated to

Figure 1.1 Four Bad Bears Adjusted for Inflation

Source: Advisor Perspectives, Inc. (C) 2014.

The updated original online version for this chapter can be found at http://dx.doi.org/10.1057/9781137503244_1 